\title{
L-Arginine Metabolism in the Lung: Reciprocal Regulation of the NOS and Arginase Pathways
}

\author{
Michelle L. North*,\#,1 and Jeremy A. Scott ${ }^{1,2,3,4,5}$
}

\author{
${ }^{I}$ Institute of Medical Science, Faculty of Medicine, University of Toronto, Toronto, ON; Canada; ${ }^{2}$ Divisions of \\ Occupational and Respiratory Medicine, Department and Faculty of Medicine, University of Toronto, Toronto, ON; \\ ${ }^{3}$ Gage Occupational and Environmental Health Unit, University of Toronto and St. Michael's Hospital, Toronto, ON; \\ ${ }^{4}$ Keenan Research Centre in the Li Ka Shing Knowledge Institute of St. Michael's Hospital, Toronto, ON; ${ }^{5}$ Division of \\ Occupational and Environmental Health, Dalla Lana School of Public Health, Faculty of Medicine, University of \\ Toronto, Toronto, $\mathrm{ON}$.
}

\begin{abstract}
It has been known for 20 years that the production of nitric oxide (NO) by the NO synthase (NOS) isozymes is important in the maintenance of airways tone. Over the past decade, however, it has become increasingly apparent that competition between the NOS and arginase pathways for L-arginine, limits NO production. Imbalances between these pathways have been implicated in the airways hyperresponsiveness (AHR) of asthma. Thus, a delicate balance between the NOS and arginase pathways is maintained through the intracellular synthesis of endogenous NOS and arginase inhibitors. More recently, the liberation of methylarginines has emerged as an additional modifier of L-arginine uptake and metabolism in the lung. In this review we discuss the reciprocal regulation of the NOS and arginase pathways and methylarginines and their roles in the airways hyperresponsiveness of asthma.
\end{abstract}

Keywords: Nitric Oxide, arginase, methylarginine, ADMA, airways reactivity

\section{BACKGROUND}

Nitric oxide (NO) is an important signaling molecule that promotes relaxation of airway smooth muscle in the respiratory system. Recent reviews have focused on the role of the arginase pathway in regulating NO production in the airways, through limitation of L-arginine bioavailability [14]. In this mini-review, we briefly introduce the roles of the nitric oxide synthase (NOS) and arginase pathways in lung homeostasis and disease, and focus on new studies suggesting therapeutic potential for targeting L-arginine metabolism in asthma, and the roles of endogenously produced NOS inhibitors.

\section{Nitric Oxide Synthase}

Nitric oxide (NO) is a gaseous non-polar free radical that can diffuse freely across biological membranes [5]. These properties make it an effective signaling molecule, requiring no specific receptors or targeted degradation [6]. Although more stable than other biologically relevant free radicals, such as peroxynitrite and superoxide [7], under physiological conditions NO reacts quickly with heme and thiol groups on biological macromolecules to regulate protein function and exert physiological effects, such as smooth muscle relaxation [8]. NO also reacts quickly with oxygen to form nitrite and nitrate as stable end products [7]. Thiol groups on biological

\footnotetext{
*Address correspondence to this author at the Department of Microbiology \& Immunology, Queens University, Kingston, Ontario, Canada; Tel: (613) 770-0262; Fax; (613) 533-6796; E-mail: northm@queensu.ca ${ }^{\#}$ Present Address: Department of Microbiology \& Immunology, Queen's University, Kingston, ON, Canada.
}

small molecules can react with NO, producing $S$-nitrosothiols (SNO) [9], such as $S$-nitrosoglutathione (GSNO), which is produced by the reaction of $\mathrm{NO}$ and glutathione and is actually present at higher concentrations than free NO in the normal airway, due to its increased stability [10]. GSNO and other SNOs act as a stable store of bioavailable NO $[6,11]$. Since its discovery in the cardiovascular system, NO signaling has been found to be involved in many homeostatic and pathologic processes in the respiratory system [2].

The constitutive nitric oxide synthase (NOS) isozymes, NOS1 and NOS3, produce picomolar amounts of NO when activated by increased intracellular calcium levels evoked by membrane depolarization or by contractile agonists (Fig. 1A) [5]. NOS requires nicotinamide adenine dinucleotide phosphate (NADPH) and molecular oxygen as co-substrates and flavin-adenine dinucleotide, flavin mononucleotide, and tetrahydrobiopterin as cofactors $[5,12]$. When NO is produced by the constitutive isozymes, the main action is signal transduction leading to smooth muscle relaxation [13]. The best characterized signal transduction pathway is initiated when NO diffuses from lung epithelial cells or nonadrenergic non-cholinergic neurons into adjacent smoothmuscle cells, coordinating with the heme group of guanylyl cyclase and activating it to produce cyclic guanosine monophosphate (cGMP) from guanosine triphosphate (Fig. 1A) [14]. The increased cGMP leads to smooth-muscle relaxation through the activation of cGMP-dependent protein kinase, reducing intracellular calcium levels and decreasing the sensitivity of the contractile elements to intracellular calcium [13]. NO also mediates relaxing effects that are independent of guanylyl cyclase [15], through the formation of SNOs, as described above. Thus, the low levels of NO 
Figure 1

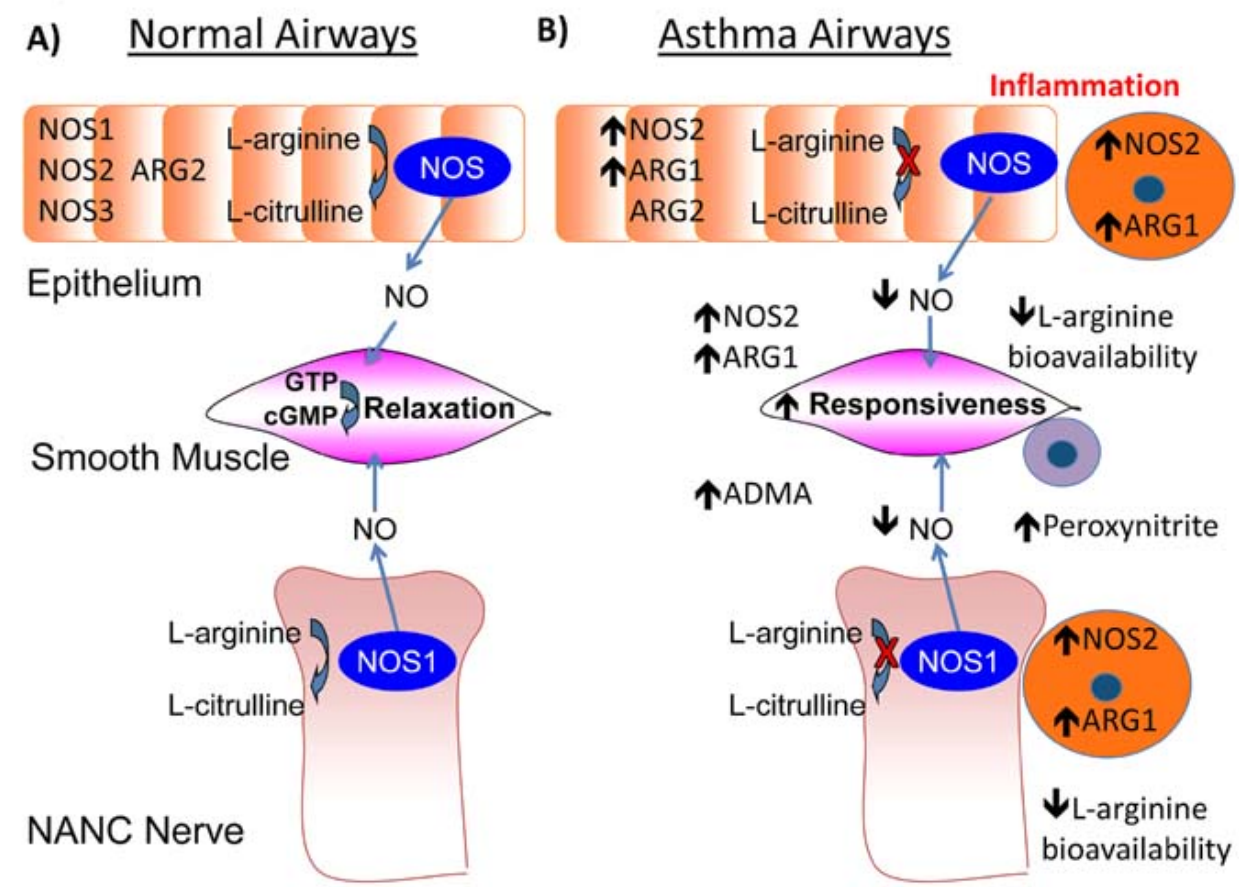

Fig. (1). A) In normal airways NOS1 is expressed in epithelial and nerve cells. Epithelial cells also express NOS2 and NOS3 constitutively. ARG2 is expressed constitutively in many extrahepatic cells types. B) In asthmatic airways, NOS2 and ARG1 are upregulated in epithelial cells, smooth muscle cels and inflammatory cells. L-arginine bioavailability is decreased and NO synthesis is impaired. ADMA and peroxynitrite concentrations are increased.

produced under homeostatic conditions promote the maintenance of the low-pressure pulmonary circulation and moderate bronchomotor tone [16-18].

Under conditions of inflammation, NOS2 is induced in smooth muscle, fibroblasts, macrophages, neutrophils and mast cells in the lung (Fig. 1B) [19-23]. NOS2 is regulated at the transcriptional level by proinflammatory cytokines, i.e., tumour necrosis factor (TNF- $\alpha$ ), IFN- $\gamma$ or IL- $1 \beta$, and produces nanomolar levels of NO [13]. Calmodulin binds tightly to NOS2 at basal calcium levels (as described in detail by Spratt et al. in this issue), and persistently activates this isozyme [24]. Activation of NOS2 is sustained for hours to days after the protein is induced [6]. High levels of NO are effective in killing pathogens, and inhibiting tumour growth [12]. However, such cytotoxic levels of NO also have the potential to damage lung tissues (Fig. 2B). Furthermore, under conditions of substrate limitation for NOS, uncoupling of the enzyme can occur, resulting in the generation of superoxide from the reductase domain [25]. NO can also react with superoxide free radicals to produce peroxynitrite, a powerful oxidant (Fig. 1B) [26]. This both disrupts the normal bioactivity of NO and results in the oxidation of biomolecules, including tyrosine residues in proteins, contributing to increased nitrosative stress in inflamed tissues [6]. Peroxynitrite can also directly evoke airways hyperresponsiveness and cause cellular damage leading to further potentiation of inflammation [27]. Thus, while low levels of NO produced by the NOS isozymes promote the maintenance of airway homeostasis, the dramatically increased levels of NO produced by NOS2 during inflammation can have damaging effects.

\section{Arginase}

The two arginase isozymes, arginase 1 and 2 are hydrolytic enzymes that metabolize L-arginine into Lornithine and urea [28]. Arginase 1 and 2 function as homotrimers, and require manganese as a cofactor [28, 29]. Although the arginase isozymes share $58 \%$ sequence homology/identity, they exhibit different organ-specific and intracellular expression patterns [29]. Arginase 1 is a cytoplasmic enzyme that is highly constitutively expressed in the liver and is inducible in other cell types, such as macrophages and epithelial cells [28, 30]. Arginase 2 is localized to the mitochondria and is expressed in many extrahepatic cell types [31]. Although arginase plays a vital role in cellular metabolism, through the production of urea for the urea cycle [32], its role in the normal and pathological function of the respiratory system has recently become an area of intense research.

\section{The Delicate Balance Between the NOS and Arginase Pathways}

Reciprocal regulation of the NOS and arginase pathways can be demonstrated at many different levels. The primary mechanism by which arginase is currently believed to affect NOS activity is by reducing the bioavailability of L-arginine substrate, at both the tissue and intracellular level (i.e., in tissues and cells in which both isozyme families are expressed, described in the following section) [33]. Evidence for this comes from several studies showing that arginase inhibition or exogenous L-arginine administration decreases airways hyperresponsiveness [30, 34-38]. Furthermore, cationic amino acids, including L-ornithine, the product of arginase, can also compete with L-arginine for uptake via the 


\section{Figure 2}

A)

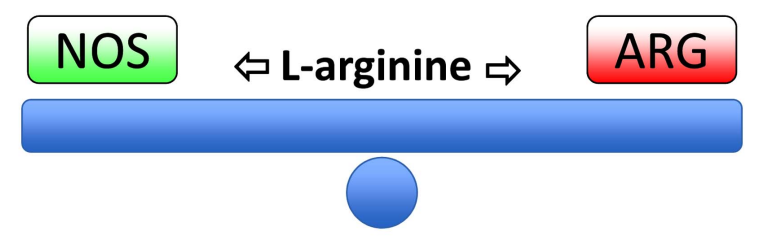

Homeostasis

B)

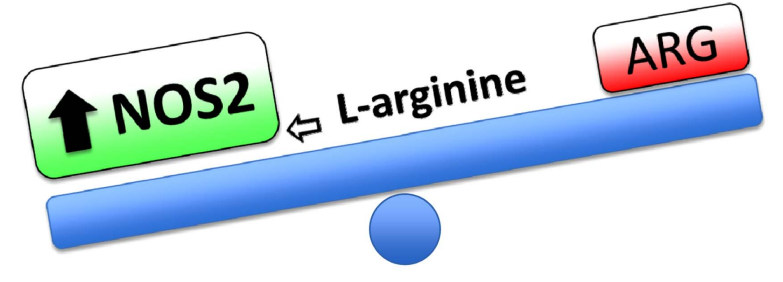

Inflammation / Cytotoxicity

C)

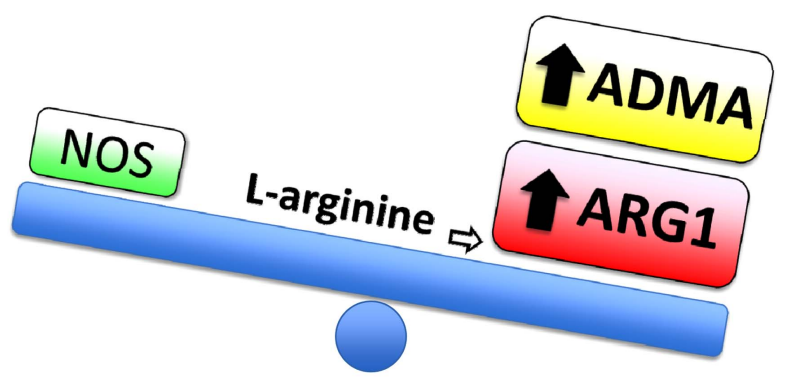

Impairment of NO synthesis

Fig. (2). A) The nitric oxide synthase and arginase pathways share a common substrate, L-arginine, and participate in a delicate balance in lung homeostasis. B) NOS2 is upregulated by pro-inflammatory stimuli and can tilt the balance towards inflammation and cytotoxicity. C) Upregulation of arginase 1 and increased levels of the endogenous NOS inhibitor ADMA can independently or collaboratively tilt the balance and impair the synthesis of NO.

CAT transporters [39, 40], also leading to intracellular substrate depletion. Thus, in asthma L-arginine metabolism is likely skewed towards increased arginase activity, resulting in a deficiency in L-arginine bioavailability for the NOS isozymes (Fig. 1B).

There are also several levels at which NOS activity is able to modify the activity of the arginase isozymes. Firstly, NO can postranslationally modify the arginase isozymes by $S$-nitrosylation, which leads to increased stability of the arginase trimer and hence increased activity [41]. NOS can also inhibit arginase activity through production of the reactive intermediate, $N$-hydroxy-L-arginine (NOHA), which is a competitive arginase inhibitor [42]. This tight reciprocal regulation of NOS and arginase activities suggest the essential nature of these two pathways in homeostasis.

NOS vs. Arginase in the lung: Localization and Functional Implications

\section{Homeostasis}

When L-arginine metabolism is balanced, as in (Fig. 2A), sufficient substrate availability allows the constitutive NOS isozymes to produce low levels of NO, which contributes to homeostasis in the lung. Under homeostatic conditions, a wide variety of pulmonary cells express NOS and release $\mathrm{NO}$, including vascular endothelial cells, airway epithelial cells and nerves (Fig. 1A) [23]. Specifically, the NOS1 isozyme is present in the airway epithelium and nonadrenergic non-cholinergic (NANC) neurons surrounding both airways and blood vessels (Fig. 1A) [21-23, 43]. Although inducible in many cell types, NOS2 is constitutively present in airway epithelial cells (Fig. 1A) [20, 21]. NOS3 is expressed in endothelial and epithelial cells (Fig. 1A) [44]. The low levels of NO produced under homeostatic conditions are important in the maintenance of proper bronchomotor tone, including regulation of blood flow, neurotransmission, and regulation of bronchomotor tone [6].

Arginase also plays a role in the homeostasis of the pulmonary system. Arginase 2 is constitutively expressed in most extrahepatic cell types (Fig. 1A) [1]. The product of arginase, L-ornithine, is converted by ornithine aminotransferase into proline, one of the building blocks of collagen and other proteins [45]. Furthermore, L-ornithine is 


\section{Figure 3}

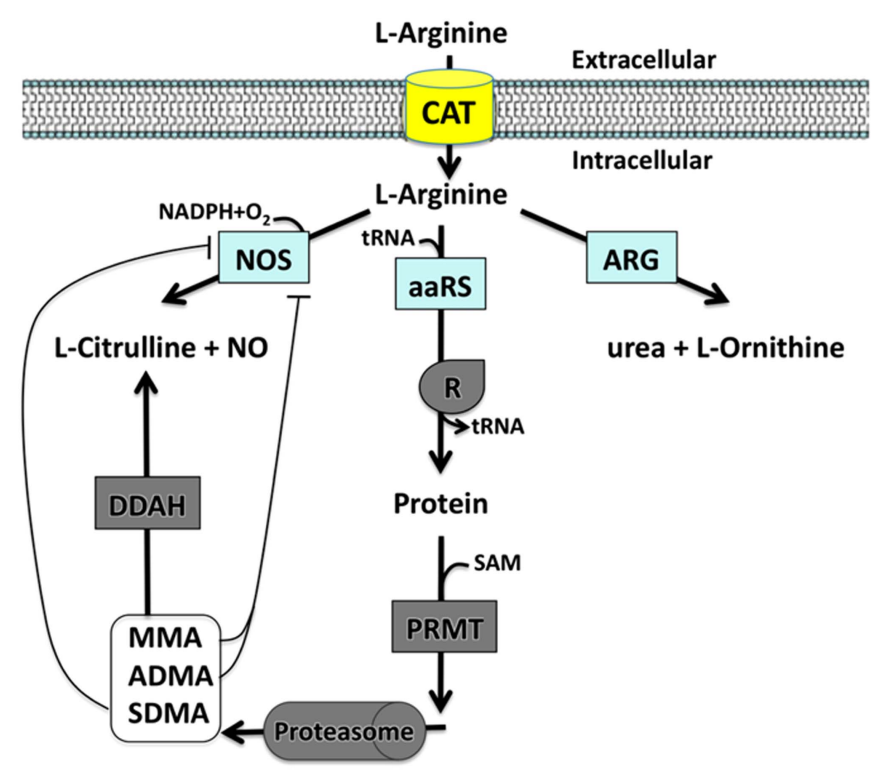

Fig. (3). L-arginine is incorporated into protein, through the action of aminoacyl tRNA synthetase (aaRS) and the ribosome (R). L-arginine residues in proteins can be methylated by protein arginine methyltransferases (PRMT). Upon breakdown of these proteins, often via proteasomal degradation, the endogenous NOS inhibitors, monomethylarginine (MMA) and asymmetric dimethylarginine (ADMA) are released. Symmetric dimethylarginine (SDMA) is also produced, and can inhibit L-arginine uptake into the cell through the CAT transporters

also converted by ornithine decarboxylase into polyamines, which are essential for cell growth and proliferation [46]. Thus, the metabolism of L-arginine via arginase plays an important role in normal cell growth as well as wound healing [47].

\section{Inflammation}

Under Th2 type inflammatory conditions, arginase 1 is induced and can skew the balance of L-arginine metabolism away from NO production, as in (Fig. 2C). Corraliza and Modolell first reported the induction of arginase 1 in murine macrophages by Th2 cytokines [48, 49]. Further studies revealed that arginase 1 is induced by IL-4 and IL-13 via a STAT6-dependent enhancer-mediated mechanism [50, 51]. Arginase 1 expression has been shown in human airway epithelial cells and smooth muscle cells in bronchoscopy samples from asthmatic subjects (Fig. 1B) [52, 53]. Thus, arginase and NOS1 may be in competition for intracellular L-arginine pools within the same cells, and under conditions of inflammation this competition may be exacerbated. Additionally, infiltrating inflammatory cells have been shown to express high levels of both NOS2 and arginase 1 (Fig. 1B) $[30,48,49]$. The presence of increased inflammatory cells may therefore also be involved in further decreasing the extracellular L-arginine bioavailability for transport into smooth muscle cells and epithelia, and increasing levels of peroxynitrite. In addition, arginase has recently been shown to be involved in airways remodeling in a guinea pig sensitization and challenge model of asthma [54]. Thus, arginase has been implicated in the pathophysiology of asthma and inhibition of this pathway has been suggested as a potential novel therapeutic target.

\section{Subcellular Localization}

As NOS and arginase can be expressed within the same cell types, subcellular localization of the enzymes also merits consideration. NOS1 contains a PDZ domain that participates in the formation of active dimers and interactions with other proteins [55]. NOS1 has been localized to the cytosol, neuronal synapses and the plasma membrane [56]. In contrast, NOS2 has a relatively wideranging distribution in various cell types, including the cytosol, perinuclear space, plasma membrane and mitochondria [57-59]. NOS3 has been demonstrated at the plasma membrane, where it exhibits complex interactions with caveolin and CAT1 [55, 60-62]. Similar to NOS2, NOS3 has also been reported to be present in mitochondria [59]. Meanwhile, arginase 1 is localized primarily in the cytosol, while arginase 2 is confined to the mitochondria [63]. Thus, there is potential for competing subcellular colocalization between these isozyme families to contribute to their respective enzyme activities. Both arginase 1 and 2 have been implicated in regulating NOS1 activity through the depletion of intracellular L-arginine [64, 65]. In cultured endothelial cells arginase 2 has been demonstrated to regulate the activity of NOS3, and this regulation has been shown to take place within non-freely exchangeable Larginine pools [66, 67]. Furthermore, over expression of arginase 1 has been demonstrated to result in impaired NO production by NOS1 in cultured 293 embryonic kidney cells stably transfected with NOS1 [65]. In a recent paper, Ckless et al. investigated the colocalization of ARG1 with NOS isozymes in C10 murine alveolar type II epithelial cells [68]. Through immunoprecipitation it was demonstrated that ARG1 colocalized with NOS3, but not NOS1 or NOS2 in 
this cell type [68]. While further exploration of the colocalization of NOS and ARG isozymes in different cell types in the lung is warranted, these studies suggest the possibility for competition for non-freely exchangeable Larginine pools to occur.

\section{Endogenous NOS Inhibition and L-Arginine Metabolism}

Accumulating evidence suggests that, in addition to the upregulation of arginase in asthma, endogenous NOS inhibitors may also play a role in the dysregulation of Larginine metabolism. L-Arginine is metabolized by aminoacyl tRNA synthetase (aaRS) into arginine-tRNA, which is then incorporated into protein (Fig. 3). Methyl groups are then added to L-arginine residues in proteins by a family of enzymes called protein arginine methyltransferases (PRMTs) [69]. Protein arginine methylation represents an important post-translational modification that may play a role in protein conformation, activity, signal transduction, and protein translocation [69]. Proteolytic hydrolysis of proteins containing these methylated arginine residues results in the liberation of $\mathrm{N}^{\mathrm{G}}$-monomethyl-L-arginine (LNMMA), asymmetric dimethylarginine (ADMA), and symmetric dimethylarginine (SDMA) (Fig. 3) [70]. ADMA and L-NMMA are known to be endogenous inhibitors of NOS that can also promote uncoupling of the enzyme [71, 72]. Additionally, SDMA competes with L-arginine transport through the CAT transporters and therefore may reduce Larginine bioavailability [73-75]. While L-NMMA and ADMA are degraded to L-citrulline and methylamines by dimethylarginine dimethylaminohydrolases (DDAH1 and DDAH2) (Fig. 3) [70], SDMA is eliminated through renal excretion [76]. Examination of PRMT expression and DDAH activity have recently revealed the lung as a major source of ADMA [75]. Thus, endogenous NOS inhibitors likely participate in the regulation of the delicate balance of L-arginine metabolism in the airways and systemically.

Endogenous ADMA production has recently been shown to be upregulated in a murine model of allergic airways inflammation [77]. Ahmad et al. demonstrated increased expression of PRMT2 and increased ADMA in the lungs of allergically inflamed mice [77]. Additionally, exogenous administration of ADMA to lung epithelial cells in vitro has been demonstrated to lead to uncoupling of NOS, resulting in the formation of superoxide [72]. Furthermore, chronic (2week) exogenous administration of ADMA to mice resulted in increased arginase activity, collagen deposition and increased airways responsiveness to methacholine [78]. Further studies from the same group have recently shown that infusion concurrent with an ovalbumin sensitization and challenge regimen potentiates allergic inflammation [79]. This further suggests that ADMA likely takes part in the reciprocal regulation of NOS and arginase (Fig. 2C). Thus, the balance between NOS activity, arginase activity and accumulation of endogenous inhibitors of these respective enzymes may be important to understand the underlying pathologic mechanisms of asthma.

\section{Other L-Arginine Related Pathways}

The metabolic versatility of L-arginine is evident in the multiple pathways that diverge from this single semiessential amino acid. In addition to the NOS, arginase and aaRS pathways, L-arginine can also be metabolized via arginine decarboxylase and arginine:glycine amidinotransferase into agmatine and creatine, respectively [63]. The conversion of L-arginine into agmatine is the most recently demonstrated pathway of L-arginine metabolism in mammals, and its significance in health and disease remains largely unknown [80]. In addition to a direct agonist effect on imidazoline receptors, agmatine also represents an alternative pathway for the synthesis of polyamines, as it is converted into putrescine and urea by agmatinase, a member of the arginase superfamily [81]. Interestingly, agmatine is also capable of inducing antizyme, and thus paradoxically reduces cellular polyamine content and proliferation through inhibition of ornithine decarboxylase [82]. Agmatine has been proposed to be involved in the transition between inflammatory NOS2 expression and the onset of the arginase-mediated repair phase [80], however the role of this L-arginine metabolite in asthma remains unknown, and future studies are needed to understand its contribution the delicate balance of L-arginine metabolism.

\section{CONCLUSIONS}

In summary, there is a delicate balance between the metabolism of L-arginine by the NOS and arginase pathways. As NO is important for the maintenance of bronchomotor tone in the airways, dysregulation of Larginine metabolism leading to substrate deficiency or inhibition of NOS can promote bronchoconstriction in airways disease. Recent studies have implicated increased concentrations of the endogenous NOS inhibitor, ADMA, in the pathogenesis of asthma. Further studies are necessary to fully understand the role of ADMA and other L-arginine metabolites in diseases of the airways.

\section{ACKNOWLEDGEMENTS}

M.N. is supported by a Canadian Institutes of Health Research Frederick Banting and Charles Best Doctoral Award.

\section{CONFLICT OF INTEREST}

The authors declare that they have no conflicts of interest relevant to this article.

\section{REFERENCES}

[1] Morris, S. M., Jr. Recent advances in arginine metabolism: roles and regulation of the arginases. Br. J. Pharmacol., 2009, 157, 922930.

[2] Maarsingh, H.; Zaagsma, J.; Meurs, H. Arginase: a key enzyme in the pathophysiology of allergic asthma opening novel therapeutic perspectives. Br. J. Pharmacol., 2009, 158, 652-664.

[3] North, M. L.; Meurs, H.; Zaagsma, J.; Scott, J.A.; Maarsingh, H. Arginase in asthma - recent developments in animal and human studies. Open Nitric Oxide J., 2010, 2, 20-36.

[4] Maarsingh, H.; Pera, T.; Meurs, H. Arginase and pulmonary diseases. Naunyn. Schmiedebergs. Arch. Pharmacol., 2008, 378, 171-184.

[5] Loscalzo, J. Nitric Oxide and the Cardiovascular System. In Contemporary Cardiology; Loscalzo, J.; Vita, J., Eds.; Humana Press Inc: New Jersey, 2000, Vol. 4, pp. 601-614.

[6] Ricciardolo, F. L. Multiple roles of nitric oxide in the airways. Thorax, 2003, 58, 175-182.

[7] Gross, S. S.; Wolin, M. S. Nitric oxide: pathophysiological mechanisms. Annu. Rev. Physiol., 1995, 57, 737-769.

[8] Gaston, B.; Drazen, J. M.; Jansen, A.; Sugarbaker, D. A.; Loscalzo, J.; Richards, W.; Stamler, J. S. Relaxation of human bronchial smooth muscle by S-nitrosothiols in vitro. J. Pharmacol. Exp. Ther., 1994, 268, 978-984. 
[9] Kharitonov, V. G.; Sundquist, A. R.; Sharma, V. S. Kinetics of nitrosation of thiols by nitric oxide in the presence of oxygen. $J$. Biol. Chem., 1995, 270, 28158-28164.

[10] Gaston, B.; Reilly, J.; Drazen, J. M.; Fackler, J.; Ramdev, P.; Arnelle, D.; Mullins, M. E.; Sugarbaker, D. J.; Chee, C.; Singel, D. J.; Loscalzo, J., Stamler, J.S. Endogenous nitrogen oxides and bronchodilator S-nitrosothiols in human airways. Proc. Natl. Acad. Sci.U S A., 1993, 90, 10957-10961.

[11] White, T. A.; Walseth, T. F.; Kannan, M. S. Nitric oxide inhibits ADP-ribosyl cyclase through a cGMP-independent pathway in airway smooth muscle. Am. J. Physiol. Lung. Cell. Mol. Physiol., 2002, 283, L1065-L1071.

[12] Moncada, S.; Higgs, A. The L-arginine-nitric oxide pathway. $N$ Engl. J. Med., 1993, 329, 2002-2012.

[13] Ricciardolo, F. L.; Sterk, P. J.; Gaston, B.; Folkerts, G. Nitric oxide in health and disease of the respiratory system. Physiol. Rev., 2004, 84, 731-765.

[14] Hobbs, A. J.; Ignarro, L.J. The Nitric Oxide - Cyclic GMP Signal Transduction System. In Nitric Oxide and the Lung; Zapol, W.M.; Bloch, K.D., Eds.; Dekker: New York, 1997; pp. 1-57.

[15] Perkins, W. J.; Pabelick, C.; Warner, D. O.; Jones, K. A. cGMPindependent mechanism of airway smooth muscle relaxation induced by S-nitrosoglutathione. Am. J. Physiol., 1998, 275, C468C474.

[16] Scott, J. A.; Craig, I.; McCormack, D. G. Nonadrenergic noncholinergic relaxation of human pulmonary arteries is partially mediated by nitric oxide. Am. J. Respir. Crit. Care. Med., 1996, 154, 629-632.

[17] Scott, J. A.; McCormack, D. G. Nonadrenergic noncholinergic vasodilation of guinea pig pulmonary arteries is mediated by nitric oxide. Can. J. Physiol. Pharmacol., 1999, 77, 89-95.

[18] McCormack, D. G.; Crawley, D. E.; Evans, T. W. New perspectives in the pulmonary circulation and hypoxic pulmonary vasoconstriction. Pulm. Pharmacol., 1993, 6, 97-108.

[19] Robbins, R. A.; Barnes, P. J.; Springall, D. R.; Warren, J. B.; Kwon, O. J.; Buttery, L. D.; Wilson, A. J.; Geller, D. A.; Polak, J. $M$. Expression of inducible nitric oxide in human lung epithelial cells. Biochem. Biophys. Res. Commun., 1994, 203, 209-218.

[20] Guo, F. H.; De Raeve, H. R.; Rice, T. W.; Stuehr, D. J.; Thunnissen, F. B.; Erzurum, S. C. Continuous nitric oxide synthesis by inducible nitric oxide synthase in normal human airway epithelium in vivo. Proc. Natl. Acad. Sci. US A., 1995, 92, 7809-7813.

[21] Asano, K.; Chee, C. B.; Gaston, B.; Lilly, C. M.; Gerard, C.; Drazen, J. M.; Stamler, J. S. Constitutive and inducible nitric oxide synthase gene expression, regulation, and activity in human lung epithelial cells. Proc. Natl. Acad. Sci. U S A., 1994, 91, 1008910093.

[22] Kobzik, L.; Bredt, D. S.; Lowenstein, C. J.; Drazen, J.; Gaston, B.; Sugarbaker, D.; Stamler, J. S. Nitric oxide synthase in human and rat lung: immunocytochemical and histochemical localization. $\mathrm{Am}$. J. Respir. Cell. Mol. Biol., 1993, 9, 371-377.

[23] Gaston, B.; Kobzik, L.; Stamler, J.S. Distribution of Nitric Oxide Synthase in the Lung. In Nitric Oxide and the Lung; Zapol, W.M.; Bloch, K.D., Eds.; Dekker: New York 1997; pp. 75-86.

[24] Cho, H. J.; Xie, Q. W.; Calaycay, J.; Mumford, R. A.; Swiderek, K. M.; Lee, T. D.; Nathan, C. Calmodulin is a subunit of nitric oxide synthase from macrophages. J. Exp. Med., 1992, 176, 599-604.

[25] Xia, Y.; Roman, L. J.; Masters, B. S.; Zweier, J. L. Inducible nitricoxide synthase generates superoxide from the reductase domain. $J$. Biol. Chem., 1998, 273, 22635-22639.

[26] Beckman, J. S.; Koppenol, W. H. Nitric oxide, superoxide, and peroxynitrite: the good, the bad, and ugly. Am. J. Physiol., 1996, 271, C1424-C1437.

[27] Sadeghi-Hashjin, G.; Folkerts, G.; Henricks, P. A.; Verheyen, A. K.; van der Linde, H. J.; van Ark, I.; Coene, A.; Nijkamp, F. P. Peroxynitrite induces airway hyperresponsiveness in guinea pigs in vitro and in vivo. Am. J. Respir. Crit. Care. Med., 1996, 153, 1697 1701.

[28] Jenkinson, C. P.; Grody, W. W.; Cederbaum, S. D. Comparative properties of arginases. Comp. Biochem. Physiol. B. Biochem. Mol. Biol., 1996, 114, 107-132.

[29] Morris, S. M., Jr.; Bhamidipati, D.; Kepka-Lenhart, D. Human type II arginase: sequence analysis and tissue-specific expression. Gene, 1997, 193, 157-161.
[30] North, M. L.; Khanna, N.; Marsden, P. A.; Grasemann, H.; Scott, J. A. Functionally important role for arginase 1 in the airway hyperresponsiveness of asthma. Am. J. Physiol. Lung. Cell. Mol. Physiol., 2009, 296, L911-L920.

[31] Wu, G.; Morris, S. M., Jr. Arginine metabolism: nitric oxide and beyond. Biochem. J., 1998, 336, 1-17.

[32] Krebs, H. A. The Discovery of the Ornithine Cycle. In The Urea Cycle; Grisolia, S.; Baguena, R.; Mayor, F., Eds.; Wiley \& Sons: New York, 1976, pp. 1-12.

[33] Hey, C.; Wessler, I.; Racke, K. Nitric oxide synthase activity is inducible in rat, but not rabbit alveolar macrophages, with a concomitant reduction in arginase activity. Naunyn Schmiedebergs Arch. Pharmacol., 1995, 351, 651-659.

[34] Mabalirajan, U.; Ahmad, T.; Leishangthem, G. D.; Joseph, D. A.; Dinda, A. K.; Agrawal, A.; Ghosh, B. Beneficial effects of high dose of L-arginine on airway hyperresponsiveness and airway inflammation in a murine model of asthma. J. Allergy Clin. Immunol., 2010, 125, 626-635.

[35] Kenyon, N. J.; Bratt, J. M.; Linderholm, A. L.; Last, M. S.; Last, J. A. Arginases I and II in lungs of ovalbumin-sensitized mice exposed to ovalbumin: sources and consequences. Toxicol. Appl. Pharmacol., 2008, 230, 269-275.

[36] Bratt, J. M.; Franzi, L. M.; Linderholm, A. L.; Last, M. S.; Kenyon, N. J.; Last, J. A. Arginase enzymes in isolated airways from normal and nitric oxide synthase 2-knockout mice exposed to ovalbumin. Toxicol. Appl. Pharmacol., 2009, 234, 273-280.

[37] Maarsingh, H.; Zuidhof, A. B.; Bos, I. S.; van Duin, M.; Boucher, J. L.; Zaagsma, J.; Meurs, H. Arginase inhibition protects against allergen-induced airway obstruction, hyperresponsiveness, and inflammation. Am. J. Respir.Crit. Care Med., 2008, 178, 565-573.

[38] Meurs, H.; McKay, S.; Maarsingh, H.; Hamer, M. A.; Macic, L.; Molendijk, N.; Zaagsma, J. Increased arginase activity underlies allergen-induced deficiency of cNOS-derived nitric oxide and airway hyperresponsiveness. Br. J. Pharmacol., 2002, 136, 391398.

[39] Closs, E. I.; Simon, A.; Vekony, N.; Rotmann, A. Plasma membrane transporters for arginine. J. Nutr., 2004, 134, 2752S$2767 \mathrm{~S}$.

[40] Maarsingh, H.; Leusink, J.; Zaagsma, J.; Meurs, H. Role of the Lcitrulline/L-arginine cycle in iNANC nerve-mediated nitric oxide production and airway smooth muscle relaxation in allergic asthma. Eur. J. Pharmacol., 2006, 546, 171-176.

[41] Santhanam, L.; Lim, H. K.; Miriel, V.; Brown, T.; Patel, M.; Balanson, S.; Ryoo, S.; Anderson, M.; Irani, K.; Khanday, F.; Di Costanzo, L.; Nyhan, D.; Hare, J. M.; Christianson, D. W.; Rivers, R.; Shoukas, A.; Berkowitz, D. E. Inducible NO synthase dependent S-nitrosylation and activation of arginase 1 contribute to age-related endothelial dysfunction. Circ. Res., 2007, 101, 692-702.

[42] Daghigh, F.; Fukuto, J. M.; Ash, D. E. Inhibition of rat liver arginase by an intermediate in NO biosynthesis, NG-hydroxy-Larginine: implications for the regulation of nitric oxide biosynthesis by arginase. Biochem. Biophys. Res. Commun., 1994, 202, 174180 .

[43] Fischer, A.; Mundel, P.; Mayer, B.; Preissler, U.; Philippin, B.; Kummer, W. Nitric oxide synthase in guinea pig lower airway innervation. Neurosci. Lett., 1993, 149, 157-60.

[44] Shaul, P. W.; North, A. J.; Wu, L. C.; Wells, L. B.; Brannon, T. S.; Lau, K. S.; Michel, T.; Margraf, L. R.; Star, R. A. Endothelial nitric oxide synthase is expressed in cultured human bronchiolar epithelium. J.Clin. Invest., 1994, 94, 2231-2236.

[45] Wu, G.; Pond, W. G.; Flynn, S. P.; Ott, T. L.; Bazer, F. W. Maternal dietary protein deficiency decreases nitric oxide synthase and ornithine decarboxylase activities in placenta and endometrium of pigs during early gestation. J. Nutr., 1998, 128, 2395-2402.

[46] Wallace, H. M.; Fraser, A. V.; Hughes, A. A perspective of polyamine metabolism. Biochem. J., 2003, 376, 1-14.

[47] Wu, G.; Bazer, F. W.; Davis, T. A.; Kim, S. W.; Li, P.; Marc Rhoads, J.; Carey Satterfield, M.; Smith, S. B.; Spencer, T. E.; Yin, $\mathrm{Y}$. Arginine metabolism and nutrition in growth, health and disease. Amino Acids, 2009, 37, 153-168.

[48] Modolell, M.; Corraliza, I. M.; Link, F.; Soler, G.; Eichmann, K. Reciprocal regulation of the nitric oxide synthase/arginase balance in mouse bone marrow-derived macrophages by TH1 and TH2 cytokines. Eur. J. Immunol., 1995, 25, 1101-1104.

[49] Corraliza, I. M.; Soler, G.; Eichmann, K.; Modolell, M. Arginase induction by suppressors of nitric oxide synthesis (IL-4, IL-10 and 
PGE2) in murine bone-marrow-derived macrophages. Biochem. Biophys. Res. Commun., 1995, 206, 667-673.

[50] Wei, L. H.; Jacobs, A. T.; Morris, S. M., Jr.; Ignarro, L. J. IL-4 and IL-13 upregulate arginase I expression by cAMP and JAK/STAT6 pathways in vascular smooth muscle cells. Am. J. Physiol. Cell. Physiol., 2000, 279, C248-C256.

[51] Pauleau, A. L.; Rutschman, R.; Lang, R.; Pernis, A.; Watowich, S. S.; Murray, P. J. Enhancer-mediated control of macrophagespecific arginase I expression. J. Immunol., 2004, 172, 7565-7573.

[52] Bergeron, C.; Boulet, L. P.; Page, N.; Laviolette, M.; Zimmermann, N.; Rothenberg, M. E.; Hamid, Q. Influence of cigarette smoke on the arginine pathway in asthmatic airways: increased expression of arginase I. J. Allergy Clin. Immunol., 2007, 119, 391-397.

[53] Zimmermann, N.; King, N. E.; Laporte, J.; Yang, M.; Mishra, A.; Pope, S. M.; Muntel, E. E.; Witte, D. P.; Pegg, A. A.; Foster, P. S.; Hamid, Q.; Rothenberg, M. E. Dissection of experimental asthma with DNA microarray analysis identifies arginase in asthma pathogenesis. J. Clin. Invest., 2003, 111, 1863-1874.

[54] Maarsingh, H.; Dekkers, B. G.; Zuidhof, A. B.; Bos, I. S.; Menzen, M. H.; Klein, T.; Flik, G.; Zaagsma, J.; Meurs, H. Increased arginase activity contributes to airway remodelling in chronic allergic asthma. Eur. Respir. J., 2011. 38(2), 318-328.

[55] Kone, B. C.; Kuncewicz, T.; Zhang, W.; Yu, Z. Y. Protein interactions with nitric oxide synthases: controlling the right time, the right place, and the right amount of nitric oxide. Am. J. Physiol, Renal Physiol., 2003, 285, F178-F190.

[56] Forstermann, U.; Boissel, J. P.; Kleinert, H. Expressional control of the 'constitutive' isoforms of nitric oxide synthase (NOS I and NOS III). FASEB J., 1998, 12, 773-790.

[57] Navarro-Lerida, I.; Corvi, M. M.; Barrientos, A. A.; Gavilanes, F.; Berthiaume, L. G.; Rodriguez-Crespo, I. Palmitoylation of inducible nitric-oxide synthase at Cys-3 is required for proper intracellular traffic and nitric oxide synthesis. J. Biol. Chem., 2004, $279,55682-55689$.

[58] Jones, R. J.; Jourd'heuil, D.; Salerno, J. C.; Smith, S. M.; Singer, H. A. iNOS regulation by calcium/calmodulin-dependent protein kinase II in vascular smooth muscle. Am. J. Physiol. Heart Circ. Physiol., 2007, 292, H2634-H2642.

[59] Zanella, B.; Giordano, E.; Muscari, C.; Zini, M.; Guarnieri, C. Nitric oxide synthase activity in rat cardiac mitochondria. Basic Res. Cardiol., 2004, 99, 159-164.

[60] Sowa, G.; Liu, J.; Papapetropoulos, A.; Rex-Haffner, M.; Hughes, T. E.; Sessa, W. C. Trafficking of endothelial nitric-oxide synthase in living cells. Quantitative evidence supporting the role of palmitoylation as a kinetic trapping mechanism limiting membrane diffusion. J. Biol. Chem., 1999, 274, 22524-22531.

[61] Fulton, D.; Fontana, J.; Sowa, G.; Gratton, J. P.; Lin, M.; Li, K. X.; Michell, B.; Kemp, B. E.; Rodman, D.; Sessa, W. C. Localization of endothelial nitric-oxide synthase phosphorylated on serine 1179 and nitric oxide in Golgi and plasma membrane defines the existence of two pools of active enzyme. J. Biol. Chem., 2002, 277, 4277-4284.

[62] McDonald, K. K.; Zharikov, S.; Block, E. R.; Kilberg, M. S. A caveolar complex between the cationic amino acid transporter 1 and endothelial nitric-oxide synthase may explain the "arginine paradox". J. Biol. Chem., 1997, 272, 31213-31216.

[63] Morris, S. M., Jr. Arginine metabolism: boundaries of our knowledge. J. Nutr., 2007, 137, 1602S-1609S.

[64] Steppan, J.; Ryoo, S.; Schuleri, K. H.; Gregg, C.; Hasan, R. K.; White, A. R.; Bugaj, L. J.; Khan, M.; Santhanam, L.; Nyhan, D.; Shoukas, A. A.; Hare, J. M.; Berkowitz, D. E. Arginase modulates myocardial contractility by a nitric oxide synthase 1-dependent mechanism. Proc, Natl, Acad, Sci. US A., 2006, 103, 4759-4764.

[65] Que, L. G.; George, S. E.; Gotoh, T.; Mori, M.; Huang, Y. C. Effects of arginase isoforms on NO Production by nNOS. Nitric Oxide, 2002, 6, 1-8.
[66] Lim, H. K.; Ryoo, S.; Benjo, A.; Shuleri, K.; Miriel, V.; Baraban, E.; Camara, A.; Soucy, K.; Nyhan, D.; Shoukas, A.; Berkowitz, D. E. Mitochondrial arginase II constrains endothelial NOS-3 activity. Am. J. Physiol. Heart Circ. Physiol., 2007, 293, H3317-H3324.

[67] Topal, G.; Brunet, A.; Walch, L.; Boucher, J. L.; David-Dufilho, M. Mitochondrial arginase II modulates nitric-oxide synthesis through nonfreely exchangeable L-arginine pools in human endothelial cells. J. Pharmacol. Exp. Ther., 2006, 318, 1368-1374.

[68] Ckless, K.; van der Vliet, A.; Janssen-Heininger, Y. Oxidativenitrosative stress and post-translational protein modifications: implications to lung structure-function relations. Arginase modulates NF-kappaB activity via a nitric oxide-dependent mechanism. Am. J. Respir. Cell. Mol. Biol., 2007, 36, 645-653.

[69] Bedford, M. T.; Clarke, S. G. Protein arginine methylation in mammals: who, what, and why. Mol. Cell., 2009, 33, 1-13.

[70] Zakrzewicz, D.; Eickelberg, O. From arginine methylation to ADMA: a novel mechanism with therapeutic potential in chronic lung diseases. BMC. Pulm. Med., 2009, 9, 5 .

[71] MacAllister, R. J.; Whitley, G. S.; Vallance, P. Effects of guanidino and uremic compounds on nitric oxide pathways. Kidney. Int., 1994, 45, 737-742.

[72] Wells, S. M.; Holian, A. Asymmetric dimethylarginine induces oxidative and nitrosative stress in murine lung epithelial cells. Am. J. Respir. Cell. Mol. Biol., 2007, 36, 520-528.

[73] Bogle, R. G.; MacAllister, R. J.; Whitley, G. S.; Vallance, P. Induction of NG-monomethyl-L-arginine uptake: a mechanism for differential inhibition of NO synthases? Am. J. Physiol., 1995, 269, C750-C756.

[74] Closs, E. I.; Basha, F. Z.; Habermeier, A.; Forstermann, U. Interference of $\mathrm{L}$-arginine analogues with $\mathrm{L}$-arginine transport mediated by the $\mathrm{y}+$ carrier hCAT-2B. Nitric Oxide, 1997, 1, 65-73.

[75] Bulau, P.; Zakrzewicz, D.; Kitowska, K.; Leiper, J.; Gunther, A.; Grimminger, F.; Eickelberg, O. Analysis of methylarginine metabolism in the cardiovascular system identifies the lung as a major source of ADMA. Am. J. Physiol. Lung. Cell. Mol. Physiol., 2007, 292, L18-L24.

[76] Kakimoto, Y.; Akazawa, S. Isolation and identification of N-G,NG- and N-G,N'-G-dimethyl-arginine, N-epsilon-mono-, di-, and trimethyllysine, and glucosylgalactosyl- and galactosyl-deltahydroxylysine from human urine. J. Biol. Chem., 1970, 245, 57515758.

[77] Ahmad, T.; Mabalirajan, U.; Ghosh, B.; Agrawal, A. Altered asymmetric dimethyl arginine metabolism in allergically inflamed mouse lungs. Am. J. Respir. Cell. Mol. Biol., 2010, 42, 3-8.

[78] Wells, S. M.; Buford, M. C.; Migliaccio, C. T.; Holian, A. Elevated asymmetric dimethylarginine alters lung function and induces collagen deposition in mice. Am. J. Respir. Cell. Mol. Biol., 2009, 40, 179-188.

[79] Klein, E.; Weigel, J.; Buford, M. C.; Holian, A.; Wells, S. M. Asymmetric dimethylarginine potentiates lung inflammation in a mouse model of allergic asthma. Am. J. Physiol. Lung. Cell. Mol. Physiol., 2010, 299, L816-L825.

[80] Satriano, J. Arginine pathways and the inflammatory response: interregulation of nitric oxide and polyamines: review article Amino Acids, 2004, 26, 321-329.

[81] Mistry, S. K.; Burwell, T. J.; Chambers, R. M.; Rudolph-Owen, L.; Spaltmann, F.; Cook, W. J.; Morris, S. M., Jr. Cloning of human agmatinase. An alternate path for polyamine synthesis induced in liver by hepatitis B virus. Am. J. Physiol. Gastrointest. Liver Physiol., 2002, 282, G375-G381.

[82] Satriano, J.; Matsufuji, S.; Murakami, Y.; Lortie, M. J.; Schwartz, D.; Kelly, C. J.; Hayashi, S.; Blantz, R. C. Agmatine suppresses proliferation by frameshift induction of antizyme and attenuation of cellular polyamine levels. J. Biol. Chem., 1998, 273, 15313-15316. 